\title{
Sustained Virological Response After Six Weeks Treatment with a Sofosbuvir-Containing Regimen in a Patient Infected with Hepatitis C Virus Genotype 4: A Case Report
}

\author{
Nawfal R Hussein ${ }^{1, *}$ \\ ${ }^{1}$ Department of Internal Medicine, College of Medicine, University of Duhok, Duhok, Iraq \\ "Corresponding author: Nawfal R Hussein, Department of Internal Medicine, College of Medicine, University of Duhok, Duhok, Iraq. Tel: +96-475075002, E-mail: \\ nawfal.hussein@yahoo.com \\ Received 2016 August 02; Accepted 2016 August 04.
}

\begin{abstract}
Introduction: Hepatitis $\mathrm{C}$ virus (HCV) infection is a major public health problem and may lead to liver failure and cancer. New direct-acting antiviral medications (DAAs) are potent with shorter course of treatment and less side effects. However, the cost of these medications and the limited experience are the main obstacles for their use.

Case Presentation: Here, a sustained virological response(SVR) was achieved in a patient, who received interferon, ribavirin and sofosbuvir for six weeks. Medications were stopped at the sixth week of treatment due to severe depression and reduction in albumin levels.

Conclusions: This report highlighted the importance of further studies to determine the safety and optimum duration of treatment with DAAs.
\end{abstract}

Keywords: HCV, Genotype 4, Sofosbuvir, Short Course

\section{Introduction}

infection with HCV is considered a major global health problem, especially in the developing world $(1,2)$. This is because such an infection might predispose the patient to serious consequences such as liver cirrhosis, hepatocellular carcinoma and liver failure $(3,4)$. The classical treatment of chronic HCV infection consists of a combination regimen of interferon and ribavirin for 24 to 48 weeks, according to HCV genotypes. This regimen was fraught with undesirable side effects such as continuous fever, depression, etc. Also, such a regimen was contraindicated in some groups of patients such as organ transplant (5). A momentous breakthrough has been made in the management of HCV with the use of DDAs with high success rate of SVR. The US food and drug administration (FDA) approved DAAs, and these drugs are being used in America and some European countries. Sofosbuvir is a polymerase inhibitor and the first drug to come on the market. It has been used in combination with interferon and ribavirin for duration of 12 weeks. The high cost of such a combination limited its use, especially in developing countries. A 12-week course of such a combination has a cost of 84000 USD in the United States, 54000 USD in the United Kingdom and 116 910 USD in Spain (6). There is limited experience regarding the use of DAAs and their interactions with other medications. Here, we reported on a case of SVR achievement af- ter six weeks of treatment with triple therapy with interferon, ribavirin and sofosbuvir. Prior to the initiation of treatment, the patient received eltrombopag to increase the platelet count. The treatment was stopped at the sixth week due to the development of depression and low albumin levels. However, HCV-real time polymerase chain reaction (RTPCR) tests were negative 12 and 24 weeks after the cessation of treatment.

\section{Case Presentation}

A 57-year-old female was referred to the infectious disease unit of Azadi hospital, Duhok, Iraq with a history of chronic HCV. The patient had previously received pegylated interferon with ribavirin but failed to achieve SVR. Blood tests showed elevated Alanine Transaminase (ALT) (93 U/l) and Aspartate Transaminase (AST) (43 U/L), low platelet count $\left(43 \times 10^{9}\right)$ and serum albumin (3.3) and elevated INR (2.1) (Table 1). Hepatitis C Virus RTPCR showed viral load of $10000 \mathrm{IU} / \mathrm{mL}$ of genotype 4, which is the most common genotype in our region (7). Liver biopsy has notorious reputation in our society and therefore the patient refused to conduct it. This case was challenging because of the low platelet count. Eltrombopag $25 \mathrm{mg}$ qday was prescribed to elevate the platelet count. Based upon the availability and cost, it was decided to treat the patient with 
Table 1. Patient Monitoring and Selected Laboratory Results

\begin{tabular}{lcccc}
\hline Tests & $\begin{array}{c}\text { Before } \\
\text { Treatment }\end{array}$ & \multicolumn{2}{c}{ During Treatment } & \multirow{2}{*}{$\begin{array}{c}\text { 12 weeks After } \\
\text { Treatment }\end{array}$} \\
\cline { 3 - 4 } & & 4 Weeks & 6 Weeks & \\
\hline RTPCR & 10000 & Negative & Negative & Negative \\
\hline ALT & 93 & 17 & 16 & 22 \\
\hline AST & 43 & 60 & 46 & 54 \\
\hline Albumin & 3.3 & 2.6 & 2.7 & 3.1 \\
\hline INR & 2.1 & 1.6 & 2.7 & 2.4 \\
\hline platelet & 43 & 80 & 74 & 56 \\
\hline
\end{tabular}

pegylated interferon $180 \mu \mathrm{g}$, ribavirin $1000 \mathrm{mg}$ and sofosbuvir $400 \mathrm{mg}$. The platelet count was corrected to higher than $80 \times 10^{9}$ before starting the treatment. Four weeks later, the patient complained of mild depression and fatigability and the investigation showed negative HCV-RTPCR and improved ALT levels and INR (Table 1). However, a reduction in albumin level was noticed and ultrasound examination showed mild ascites. The treatment was continued and the patient was followed up weekly. Two weeks later, the patient complained of severe depression and refused to continue the treatment. All medications were stopped including eltrombopag. Four weeks later, the depression had subsided and the patient was well, clinically. Albumin level was 3.2 and ultrasound showed no ascites. All investigations were repeated 12 weeks after stopping the treatment (Table 1). It was shown that HCV-RTPCR was still negative with improvement in the levels of albumin. Real Time-PCR was repeated 24 weeks after cessation of the treatment and it was still negative.

\section{Discussion}

Chronic HCV infection might be associated with the development of hepatic failure, cirrhosis and hepatocellular carcinoma $(1,2)$. With the emergence of new directacting antiviral agents, the mainstream treatment of HCV has changed toward better tolerability and higher cure rate in comparison with the classical regimen that consisted of interferon with ribavirin. However, the high cost of DAAs limited their use especially in developing countries (8-10). Here, we presented a case with previous classical interferon and ribavirin treatment failure, who was referred to our infectious disease unit for further management. Initial investigations showed HCV-RTPCR positive results with a low viral load. The patient was treated with a triple regimen of interferon, ribavirin and sofosbuvir. This case was treated for six weeks and medications were ceased due to adverse events. However, half course (6 weeks) treatment was enough to eradicate HCV as RTPCR tests were negative, 12 and 24 weeks after the cessation of treatment.
It was noticed that the pretreatment viral load was low and this may explain the successful treatment with a shorter course of medications. Further studies are needed to confirm this observation and if approved it may help to relieve the high costs of DAAs.

Eltrombopag binds to thrombopoietin receptor and stimulates the proliferation and maturation of megakaryocytes and hence platelet production in a dose-dependent manner (11). The patients with liver cirrhosis produced by hepatitis $\mathrm{C}$ virus have thrombocytopenia. Eltrombopag increases the platelet count and allows the initiation of therapy with pegylated interferon and ribavirin and, in a significant proportion of patients, completes the proposed therapy for 12 weeks (11). This patient was taking eltrombopag that could have contributed to the low albumin level through an unknown interaction or reaction to the drug. There is a need for more studies about the safety of the use of new DAA medications with Eltrombopag

\section{Footnote}

Financial Disclosure: None to declare.

\section{References}

1. Hussein NR. Prevalence of HBV, HCV and HIV and Anti-HBs antibodies positivity in healthcare workers in departments of surgery in Duhok city, Kurdistan region, Iraq. Int J Pure Appl Sci Technol. 2015;26(6):70-5.

2. Averhoff FM, Glass N, Holtzman D. Global burden of hepatitis C: considerations for healthcare providers in the United States. Clin Infect Dis. 2012;55 Suppl 1:S10-5. doi: 10.1093/cid/cis361. [PubMed: 22715208].

3. Koshy A, Madda JP, Marcellin P, Martinot M. Treatment of hepatitis $C$ virus genotype 4-related cirrhosis: ribavirin and interferon combination compared with interferon alone. J Clin Gastroenterol. 2002;35(1):82-5. [PubMed: 12080232].

4. Legrand-Abravanel F, Colson P, Leguillou-Guillemette H, Alric L, Ravaux I, Lunel-Fabiani F, et al. Influence of the HCV subtype on the virological response to pegylated interferon and ribavirin therapy.J Med Virol. 2009;81(12):2029-35. doi:10.1002/jmv.21583. [PubMed: 19856464].

5. Hussein NR, Saleem ZS. Successful Treatment of Hepatitis C Virus Genotype 4 in Renal Transplant Recipients With Direct-Acting Antiviral Agents. Am J Transplant. 2016;16(7):2237-8. doi: 10.1111/ajt.13767. [PubMed: 26932513].

6. Yilmaz H, Yilmaz EM, Leblebicioglu H. Barriers to access to hepatitis C treatment. J Infect Dev Ctries. 2016;10(4):308-16. doi:10.3855/jidc.7849. [PubMed: 27130991].

7. Hussein NR, Tunjel I, Basharat Z, Taha A, Irving W. The treatment of HCV in patients with haemoglobinopathy in Kurdistan Region, Iraq: a single centre experience. Epidemiol Infect. 2016;144(8):1634-40. doi: 10.1017/S0950268815003064. [PubMed: 27125573].

8. Vespasiani-Gentilucci U, Galati G, Gallo P, De Vincentis A, Riva E, Picardi A. Hepatitis $C$ treatment in the elderly: New possibilities and controversies towards interferon-free regimens. World J Gastroenterol. 2015;21(24):7412-26. doi: 10.3748/wjg.v21.i24.7412. [PubMed: 26139987].

9. Hussein NR. Sofosbuvir-containing regimen for the treatment of hepatitis c virus in a patient with sickle-thalassemia: A first case report. Int J Infect. 2016;Inpress. 
10. Hussein NR, Saleem ZSM. Successful treatment of Hepatitis C virus in fection in a renal transplant patient with ribavirin and sofosbuvir: A case report. Int J Case Rep Imag. 2016;7.
11. Mihaila RG, Cipaian RC. Eltrombopag in chronic hepatitis C. World J Gastroenterol. 2014;20(35):12517-21. doi: 10.3748/wjg.v20.i35.12517. [PubMed: 25253952]. 